\title{
Theoretical study of the physicochemical properties of the light transactinides
}

\author{
V. Pershina and B. Fricke \\ Theoretical Physics Department, University of Kassel, D-34132 Kassel (Germany) \\ G.V. Ionova \\ Institute of Physical Chemistry, Russian Academy of Sciences, 117915 Moscow (Russian Federation)
}

\begin{abstract}
A theoretical study of the physicochemical properties of elements 104,105 , and 106 and their compounds in the gas phase and aqueous solutions has been undertaken using relativistic atomic and molecular codes. Trends in properties such as bonding, ionization potentials, electron affinities, energies of electronic transitions, stabilities of oxidation states etc. have been defined within the corresponding chemical groups and within the transactinides. These trends are shown to be determined by increasing relativistic effects within the groups. The behaviour of some gas phase compounds and complexes in solutions is predicted for the gas chromatography and solvent extraction experiments. Redox potentials in aqueous solutions of these elements are estimated.
\end{abstract}

\section{Introduction}

During the last 20 years the end of the periodic table has been a subject of both experimental and theoretical interest [1-7]. While systematics in electronic structure and properties of the actinides have been basically determined, the transactinide elements are at present under thorough investigation with respect to determining these systematics and to establishing the influence of relativistic effects on them.

A number of chemical experiments [6-7] have been conducted to investigate the properties of the transactinide elements relative to analogues within the lighter elements and to provide evidence for the influence of relativistic effects on their properties. Although these experiments have shown that the chemical behaviour of elements 104, 105, and 106 is characteristic of the d elements of groups 4,5 , and 6 , they revealed that the properties of the compounds within the groups do not change smoothly. For example, the volatility of halides of elements 104 and 105 change in a different way relative to analogues [6] and the behaviour of element 105 in the exchange solvent extraction experiments is similar to that of $\mathrm{Nb}$ (and $\mathrm{Pa}$ ) and not to that of Ta [7].

These interesting experimental results needed a theoretical interpretation and the general analogy in electronic structure and related properties between the transactinides and the lighter analogues had to be established independently. Furthermore, predictions of the chemical behaviour in future experiments is of special importance owing to the complexity and high costs of the experiments on the transactinides.

\section{Relativistic effects in atomic properties of elements 104, 105, and 106}

Multiconfiguration Dirac-Fock (MCDF) calculations [3-5] have shown that the change in the spatial extension and energies of orbitals in a relativistic treatment compared with a non-relativistic treatment leads to different ground state electronic configurations for $\mathbf{L r}$ and element 104 than those which would be expected on the basis of a straightforward extrapolation of the periodic system. $\mathrm{Lr}$ turned out to have a $7 \mathrm{~s}^{2} 7 \mathrm{p}_{1 / 2}$ electronic configuration instead of the expected $7 \mathrm{~s}^{2} 6 \mathrm{~d}$ configuration and element 104 to have $7 \mathrm{~s}^{2} 7 \mathrm{p}_{1 / 2} 6 \mathrm{~d}$ instead of $7 \mathrm{~s}^{2} 6 \mathrm{~d}^{2}$. Relativistic (MCDF) ground state electronic configurations for elements 105 and 106 are $6 \mathrm{~d}^{3} 7 \mathrm{~s}^{2}$ and $6 \mathrm{~d}^{4} 7 \mathrm{~s}^{2}$ respectively (Table 1 ).

The influence of relativistic effects on the energies of the valence electrons for group 5 elements as an example is shown in Fig. 1. Relativistic $7 \mathrm{~s}$ and $7 \mathrm{p}_{1 / 2}$ orbitals of $\mathrm{Ha}$ will strongly contribute to bonding with ligands owing to their low energies and spatial contraction. Non-relativistic treatment of these wavefunctions would result in the opposite trend: a decrease in 
TABLE 1. Some physicochemical data for elements 104,105 , and 106

\begin{tabular}{|c|c|c|c|c|}
\hline Property & E104 & E105 & E106 & Reference \\
\hline Chemical group & 4 & 5 & 6 & \\
\hline Ground state configuration & $6 d 7 s^{2} 7 p$ & $6 d^{3} 7 s^{2}$ & $6 d^{4} 7 s^{2}$ & $4,5,8,10$ \\
\hline First excited configuration & $6 d^{2} 7 s^{2}$ & $6 d^{3} 7 s 7 p$ & $6 d^{3} 7 s^{2} 7 p(?)$ & $8,9,10$ \\
\hline Excitation energy $(\mathrm{eV})$ & 0.24 & 1.90 & 1.64 & $4,5,8$ \\
\hline$R_{\max }\left(\mathrm{M}^{x+}\right)(\AA)$ & 0.706 & 0.685 & & \\
\hline $\operatorname{IR}\left(\mathrm{M}^{z+}\right)(\AA)$ & 0.78 & 0.74 & & \\
\hline$\Sigma^{n} I P(n=\max )(e V)$ & 76.80 & 126.38 & & 5,8 \\
\hline $\mathrm{IP}(0)-(1+)(\mathrm{eV})$ & 6.50 & 6.89 & 7.10 & $5,4,2$ \\
\hline Most stable oxidation state & $4+(1+?)$ & $5+$ & $6+(4+?)$ & \\
\hline
\end{tabular}

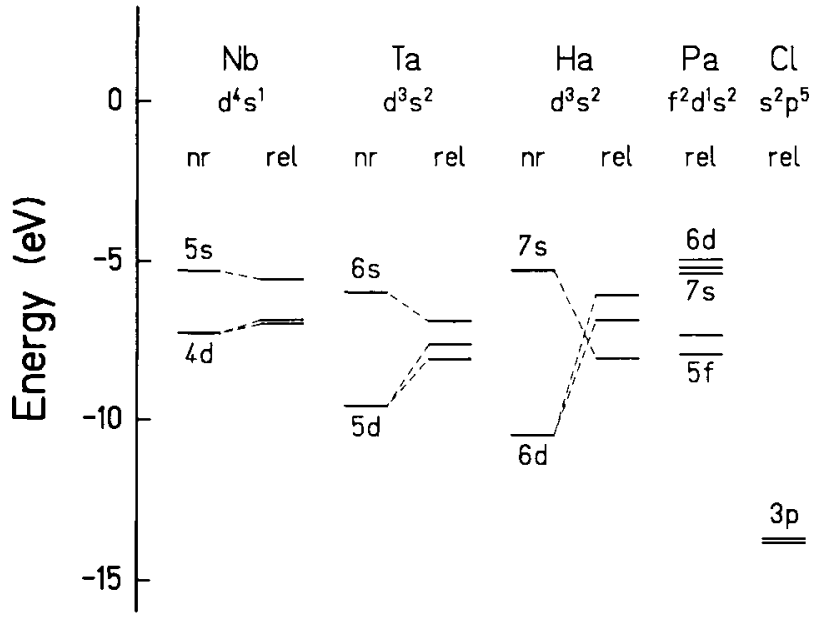

Fig. 1. Binding energies for $\mathrm{Nb}, \mathrm{Ta}$, and $\mathrm{Ha}$ as a result of the Dirac-Fock (relativistic) and Hartree-Fock (non-relativistic) calculations [11]. The relativistic energies for $\mathrm{Pa}$ are also given for comparison. (From ref. 12.)

TABLE 2. Multiple ionization potentials $(0-4+)$ and $(0-5+)$, radii of maximum radial charge density $\left(R_{\max }\right)$ and ionic radii $R_{\mathrm{i}}$ for $\mathrm{M}^{4+}$ and $\mathrm{M}^{5+\mathrm{a}}$

\begin{tabular}{|c|c|c|c|c|c|c|c|}
\hline \multirow[b]{2}{*}{ Element } & \multicolumn{3}{|c|}{ Group IV } & \multicolumn{4}{|l|}{ Group V } \\
\hline & $\begin{array}{l}\Sigma I P \\
(e V)^{b}\end{array}$ & $\begin{array}{l}R_{\max } \\
(\AA)\end{array}$ & $\begin{array}{l}R_{\mathrm{i}} \\
(\AA)^{\mathrm{c}}\end{array}$ & Element & $\begin{array}{l}\operatorname{IIP}_{(\mathrm{eV})^{\mathrm{b}}}\end{array}$ & $\begin{array}{l}R_{\max } \\
(\AA)\end{array}$ & $\begin{array}{l}R_{\mathrm{i}} \\
(\AA)^{\mathrm{c}}\end{array}$ \\
\hline $\mathrm{Ti}$ & 91.15 & 0.47 & 0.61 & V & 162.64 & 0.44 & 0.54 \\
\hline $\mathrm{Zr}$ & 77.29 & 0.62 & 0.72 & $\mathrm{Nb}$ & 135.05 & 0.59 & 0.64 \\
\hline $\mathrm{Hf}$ & 77.50 & 0.63 & 0.71 & $\mathrm{Ta}$ & 132.03 & 0.60 & 0.64 \\
\hline E104 & 76.80 & 0.71 & 0.79 & E105 & 126.38 & 0.69 & 0.74 \\
\hline
\end{tabular}

${ }^{a}$ Ref. 5,8 .

${ }^{b}$ Ref. 13 for $3 \mathrm{~d}, 4 \mathrm{~d}$, and $5 \mathrm{~d}$ elements.

${ }^{\mathrm{c}}$ Ref. 14.

their contribution to the bonding. The complete analysis of the influence of relativistic effects on the atomic and molecular properties of group 5 elements is presented in ref. 12 .

In Table 2 radii of $R_{\max }$ maximum charge density and ionic radii $R_{\mathrm{i}}$, as well as ionization potentials (IPs) for group 4 and 5 elements are given as obtained from
MCDF calculations [5, 8]. Because of the larger ionic and covalent radii and the small ionization energies, elements 104 and 105 will readily reach their maximum oxidation states and will exhibit a rich chemistry of complex ions in solutions. The same will probably hold for element 106 which is still awaiting MCDF calculations.

\section{Molecular properties of the gas phase halides and oxyhalides}

Although the early predictions $[1,2]$ of the chemical properties of the transactinides based on the results of the atomic calculations were useful at the initial stage of the investigations, relativistic molecular calculations were needed as an advanced step in studying the properties of particular compounds. These properties are bonding, molecular IPs, electron affinities, crystal field and spin-orbit effects, electron transitions, stability of oxidation states, complex formation etc.

Thus, a series of molecular orbital calculations [15-18] have been performed for halide and oxyhalide compounds of elements 104, 105, and 106 using the Dirac-Slater discrete variational (DSDV) method [19]. The Mulliken population analysis has been used to study the charge density distribution and bonding in these systems.

\subsection{Group 5 halides and oxyhalides: trends in the properties within the group}

The study of the trends in properties within the groups and investigation of the influence of relativistic effects on them have been done for the group 5 highest halides $\mathrm{MX}_{5}$, where $\mathrm{M} \equiv \mathrm{V}, \mathrm{Nb}, \mathrm{Ta}$, element 105 (Ha), and $\mathrm{Pa}$, and $\mathrm{X} \equiv \mathrm{Cl}, \mathrm{Br}$ [10-14].

The energy eigenvalues for the pentahalides as a result of the relativistic calculations are shown in Fig. 2. Analysis [12] has shown that an increase in the energy gap between the bonding and non-bonding levels, in the crystal field, and spin-orbit splittings is a result of relativity. Relativistic effects increase the energies 


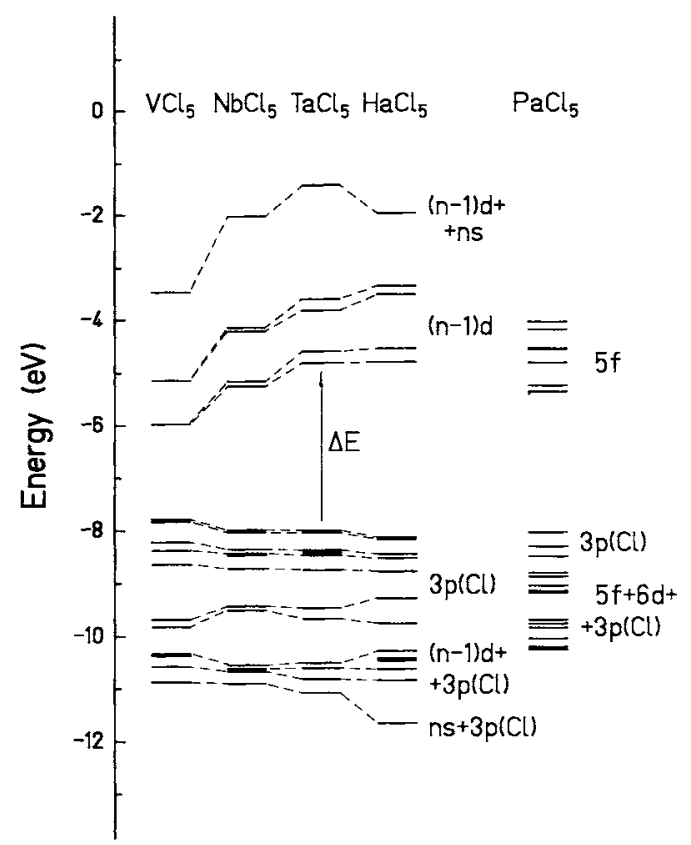

Fig. 2. Energy level structure for $\mathrm{MCl}_{5}$ molecules as a result of relativistic calculations. (From ref. 15.)

TABLE 3. Effective atomic charges $\left(Q_{M}\right)$, total (tot) and partial $(\mathrm{M}=\mathrm{O})$ overlap populations $(\mathrm{OP})^{\mathrm{a}}$, and dipole moments for $\mathrm{MCl}_{5}{ }^{\mathrm{b}}$ and $\mathrm{MOCl}_{3}^{\mathrm{c}}$

\begin{tabular}{|c|c|c|c|c|c|c|c|}
\hline \multirow[t]{2}{*}{ Element } & \multicolumn{3}{|c|}{$\mathrm{MCl}_{5}$} & \multicolumn{4}{|c|}{$\mathrm{MOCl}_{3}$} \\
\hline & $Q_{M}$ & $\mathrm{OP}($ tot $)$ & $\begin{array}{l}\mathrm{E}_{\pi-d} \\
(\mathrm{eV})\end{array}$ & $Q_{M}$ & $\mathrm{OP}(\mathrm{tot})$ & $\mathrm{OP}(\mathrm{M}=\mathrm{O})$ & $\begin{array}{l}\mu \\
\text { (D) }\end{array}$ \\
\hline V & 1.12 & 1.70 & 2.40 & 1.17 & 1.80 & 0.59 & 0.48 \\
\hline $\mathrm{Nb}$ & 0.93 & 2.04 & 2.98 & 0.98 & 1.76 & 0.63 & 0.91 \\
\hline Ta & 0.95 & 2.49 & 3.41 & 1.02 & 2.16 & 0.72 & 0.99 \\
\hline $\mathrm{Ha}$ & 0.81 & 2.60 & 3.50 & 0.90 & 2.29 & 0.79 & 1.27 \\
\hline $\mathrm{Pa}$ & 0.98 & 1.97 & 2.93 & 1.14 & 1.62 & 0.42 & 0.88 \\
\hline
\end{tabular}

${ }^{\mathrm{a}} \mathrm{OP}$ is a direct counterpart of the covalent bonding energy. ${ }^{b}$ Ref. 15.

'Ref. 17.

of the charge transfer transitions and molecular IP and decreases the electron affinity in the $6 \mathrm{~d}$ element, $\mathrm{Ha}$, but it decreases the energies of the $d-d$ transitions owing to a strong relativistic stabilization of the 7sorbital contributing to the highest vacant $d$ orbital.

Results of the charge density distribution analysis are presented in Table 3. There is a general increase in covalency in going down the group. A strong relativistic stabilization of the $7 \mathrm{~s}$ and $7 \mathrm{p}_{1 / 2}$ orbitals makes effective charges $Q_{\mathrm{M}}$ of $\mathrm{Nb}$ and Ta nearly equal and further it diminishes drastically the effective charge on $\mathrm{Ha}$ and increases its overlap population (OP) making $\mathrm{HaCl}_{5}$ highly covalent in comparison with the preceding analogues. Without relativity Ha would be rather similar to $\mathrm{V}$ (see ref. 12).
Relativistic effects increase also the stability of the maximum oxidation state in going down the group. Thus, correlation between the relativistic energies of the charge transfer transitions for $\mathrm{MCl}_{5}$ and the reduction potentials $E^{0}(\mathrm{~V}-\mathrm{IV})$ gives a potential $E^{0}(\mathrm{~V}-\mathrm{IV})$ for $\mathrm{Ha}$ of $-1.15 \mathrm{~V}$, so that the stability of the +5 oxidation state changes in the group in the following way [15]: $\mathrm{V}<\mathrm{Nb}<\mathrm{Ta}<\mathrm{Ha}$.

Electronic structure data for $\mathrm{Pa}$ halides as possible analogues of group 5 elements reveal a different nature of bonding owing to the participation of the $5 f$ orbitals.

Since the formation of the pure halides of group 5 elements is often accompanied by the formation of oxyhalides, calculations of the electronic structure of oxyhalides $\mathrm{MOX}_{3}(\mathrm{X} \equiv \mathrm{Cl}, \mathrm{Br})$ of $\mathrm{V}, \mathrm{Nb}, \mathrm{Ta}, \mathrm{Ha}$, and Pa have been carried out in ref. 17. The final results for the electron density distribution are given in Table 3. An unexpected result is that the oxyhalides turned out to be more ionic than the corresponding pentahalides. The OPs $\mathrm{M}=\mathrm{O}$ exhibit an increasing tendency to form the double bond with oxygen in going from $\mathrm{Nb}$ to $\mathrm{Ha}$.

\subsection{About the volatility of the halides and oxyhalides of $\mathrm{Nb}, \mathrm{Ta}$, and $\mathrm{Ha}$}

In ref. 16 attempts have been made to estimate the volatility of the group 5 halides. Taking into account only the covalency, the high values of the $\mathrm{OP}$ data for the symmetric $\mathrm{HaCl}_{5}$ or $\mathrm{HaBr}_{5}$ molecules compared with analogous $\mathrm{Nb}$ and $\mathrm{Ta}$ molecules could be partially a reason for their higher volatility. The oxyhalides should be less volatile owing to their lower covalency and increasing dipole moments in the direction to $\mathrm{Ha}$ (Table 3).

A more reliable measure of volatility is the temperature dependence of the equilibrium vapour pressure $P_{\mathrm{mm}}$ over a substance: $\ln P_{\mathrm{mm}}=A-B / T$.

In ref. 16 an approach was found to estimate the relation between $P_{\mathrm{mm}}$ of two analogous compounds via the relation between their intermolecular (dispersion) interactions. Thus, the relation between $P_{\mathrm{mm}}$ for $\mathrm{NbBr}_{5}$ and $\mathrm{TaBr}_{5}$ can be finally expressed in the following way:

$$
\gamma=\log \frac{P_{\mathrm{mm}}^{\mathrm{NbBrs}}}{P_{\mathrm{mm}}^{\mathrm{TaBr} s}}=\frac{273+194 Q_{\mathrm{Br}}^{\mathrm{NbBrs}}}{273+194 Q_{\mathrm{Br}}^{\mathrm{TaBrs}}}\left(\frac{1.14-0.85 Q_{\mathrm{Br}}^{\mathrm{NbBrs}}}{1.14-0.85 Q_{\mathrm{Br}}^{\mathrm{TaBrs}}}\right)^{6}
$$

giving $\log P_{\mathrm{HaBrs}}=12.5-5088 / T$. The plot of $P_{\mathrm{mm}}(\mathrm{Hg})$ vs. $T$ is shown in Fig. 3.

Estimates of the volatility as a process of adsorption-desorption of gaseous molecules in the gas chromatography experiments [6] have been given in ref. 16 . 


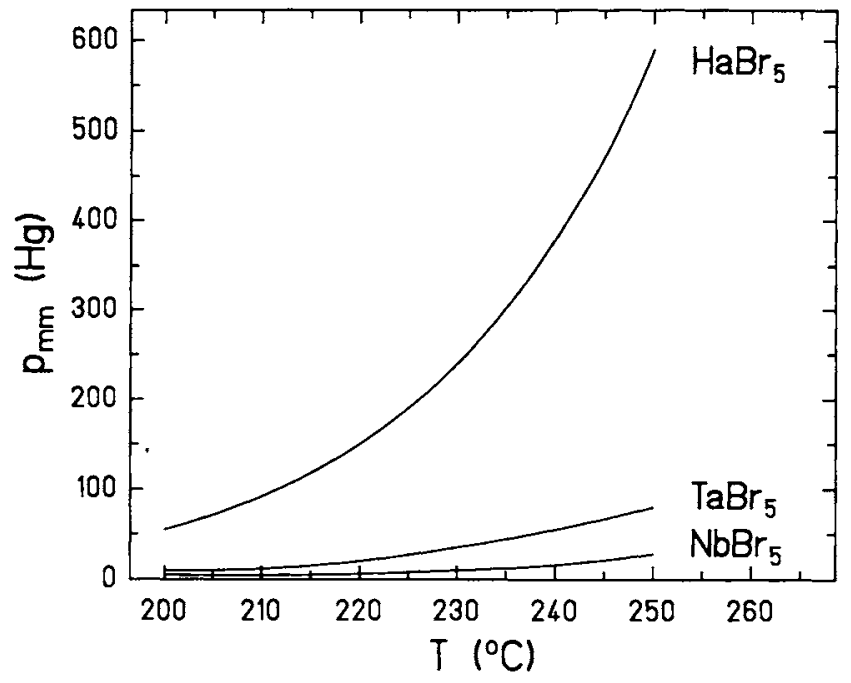

Fig. 3. Volatility as $P_{\mathrm{mm}}$ for group 5 bromides. The curve for $\mathrm{HaBr}_{5}$ is estimated. (From ref. 16.)

\subsection{Comparison of the highest halides of groups 4, 5, and 6}

In ref. 18 results of the DSDV calculations of the highest halides $\mathrm{MCl}_{4}, \mathrm{MCl}_{5}$ and $\mathrm{MCl}_{6}$ are presented for groups 4, 5, and 6 including elements 104, 105 and 106 , respectively. These data show that notwithstanding the basic similarity between the groups, there are also differences. Although the covalency increases in going down the groups, this increase diminishes with increasing atomic number of the transactinides. Thus, if $\mathrm{E} 104 \mathrm{Cl}_{4}$ is more stable to the thermal decomposition than $\mathrm{HfCl}_{4}$, $\mathrm{E} 106 \mathrm{Cl}_{6}$ will be less stable than $\mathrm{WCl}_{6}$, which decomposes at $T_{\mathrm{b}}=346^{\circ} \mathrm{C}$. Generally, the stability of the highest chlorides decreases in going from group 4 to group 6. Thus, $\mathrm{E} 106 \mathrm{Cl}_{6}$ can hardly be used as an object of investigation in the gas chromatography experiments.

In addition, the stability of the maximum oxidation state of the transactinides decreases with increasing $Z$. The correlation between energies of the charge transfer transitions in $\mathrm{MCl}_{n}$ molecules with the reduction potentials corresponding to the transitions from the maximum to the next reduced state gives the decreasing (absolute) values of the potentials evidencing that
$\operatorname{Lr}(+3)>\mathrm{E} 104(+4)>\mathrm{E} 105(+5)>\mathrm{E} 106(+6)$

(Table

\section{Solution chemistry}

\subsection{Stability of different oxidation states within the groups}

As was mentioned in the beginning, the stability of the maximum oxidation state in solutions increases in going down groups 4,5 , and 6 . A new value of $E^{0}(\mathrm{IV}-0)$ for $\mathrm{E} 104$ equal to $-1.85 \mathrm{~V}$ has been given in ref. 18 .

In ref. 20 all possible redox reactions of group 5 elements (including $\mathrm{Pa}$ ) in aqueous acid solutions have been considered and the redox potentials have been determined on the basis of the correlation between them and corresponding ionization potentials obtained from the MCDF calculations. From the values of these potentials the following sequences in the stability of different oxidation states have been established:

$\mathrm{M}^{5+}: \mathrm{V}<\mathrm{Nb}<\mathrm{Ta}<\mathrm{Ha}<\mathrm{Pa}$

$\mathrm{M}^{4+}: \mathrm{V} \gg \mathrm{Pa}>\mathrm{Nb}>\mathrm{Ta}>\mathrm{Ha}$

$\mathrm{M}^{3+}: \mathrm{V}>\mathrm{Nb}>\mathrm{Ta}>\mathrm{Ha}>\mathrm{Pa}$

$\mathrm{M}^{2+}: \mathrm{V}>\mathrm{Nb} \geqslant \mathrm{Ha}>\mathrm{Ta}>\mathrm{Pa}$

Thus, in contrast with earlier expectations, the +3 oxidation state of $\mathrm{Ha}$ in solutions will not be stable.

An estimate of the reduction potential $E^{0}\left(E 106 \mathrm{O}_{4}^{2-} / E 106 \mathrm{O}_{4}^{3-}\right)$ equal to $-1.75 \mathrm{~V}[22]$ proves an increase in the stability of the +6 oxidation state in group 6 with increasing $Z$.

\subsection{Anionic forms of the group 5 elements in acid solutions}

To find an explanation for the experimental results [7] on extraction of the group 5 halide complexes by aliphatic amines the complex formation of group 5 elements, including $\mathrm{Pa}$, has been studied [23] on the basis of the DSDV calculations of the halide and oxyhalide complexes.

TABLE 4. Standard reduction potentials $E^{0}\left(\mathrm{M}^{2+x} / \mathrm{M}^{\mathrm{z}+}\right)$ (in $\mathrm{V}$ ) for heavy elements

\begin{tabular}{lcccc}
\hline Element & $E^{0}\left(\mathrm{M}^{3+} / \mathrm{M}^{2+}\right)^{\mathrm{a}}$ & $E^{0}\left(\mathrm{M}^{4+} / \mathrm{M}^{3+}\right)^{\mathrm{a}}$ & $E^{0}\left(\mathrm{M}^{5+} / \mathrm{M}^{4+}\right)^{\mathrm{b}}$ & $E^{0}\left(\mathrm{M}^{6+} / \mathrm{M}^{5+}\right)^{\mathrm{c}}$ \\
\hline E102(No) & 1.3 & 6.6 & & \\
E103(Lr) & -2.6 & 8.1 & -1.0 & -0.93 \\
E104 & -1.7 & -1.5 & & $-1.38^{\mathrm{b}}$ \\
E105(Ha) & $-1.20^{\mathrm{b}}$ & & \\
E106 & & &
\end{tabular}

${ }^{\mathrm{a}}$ Ref. 21 .

${ }^{b}$ Ref. 20.

'Ref. 18. 
The obtained charge density distribution data exhibit qualitatively the trends found in the experiments: the specific position of $\mathrm{Ta}$ in the group (its clear preference to form pure halide complexes) and the tendency of $\mathrm{Pa}$ and $\mathrm{Ha}$ (and $\mathrm{Nb}$ at low $\mathrm{HCl}$ concentrations) to form oxyhalide complexes. In addition, a very strong trans effect in $\left[\mathrm{TaOCl}_{5}\right]^{2-}$ facilitates the substitution of oxygen atom by a chlorine atom (see ref. 23), while in $\left[\mathrm{HaOCl}_{5}\right]^{2-}$ oxygen is strongly bound. Hahnium is supposed to form also complexes with coordination number higher than 6 at high $\mathrm{HCl}$ concentrations.

The differences in the types of the formed complexes explain their different extraction by aliphatic amines (see ref. 23). Monocharged, highly covalent $\left[\mathrm{TaCl}_{6}\right]^{-}$ is extracted the best. For the oxyhalide complexes of $\mathrm{Nb}, \mathrm{Pa}$, and $\mathrm{Ha}$ the theories of Born and Bjerrum give the following sequence in their partition between the organic and aqueous phases: $\mathrm{P}\left(\mathrm{NbOCl}_{5}^{2-}\right)<$ $\mathrm{P}\left(\mathrm{HaOCl}_{5}^{2-}\right)<\mathrm{P}\left(\mathrm{PaOCl}_{5}^{2-}\right.$. The same holds for $\left[\mathrm{MOCl}_{4}\right]^{-}$and $\left[\mathrm{MO}(\mathrm{OH})_{2} \mathrm{Cl}_{4}\right]^{-}$.

\subsection{Anionic complexes of group 6 elements}

A theoretical study of group 6 oxyanions $\left[\mathrm{MO}_{4}\right]^{2-}$ $(\mathrm{M} \equiv \mathrm{Cr}, \mathrm{Mo}, \mathrm{W}$, and E106) has been undertaken [22] within the DSDV scheme. For the solid state compounds containing these oxyanions, the obtained values of the charge transfer transitions in $\left[\mathrm{E} 106 \mathrm{O}_{4}\right]^{2-}$ are indicative of a strong luminescence in the blue-violet range.

The calculations for the $\left[\mathrm{MO}_{4}\right]^{2-}$ complexes in solutions reveal an increase in $\mathrm{M}-\mathrm{O}$ bonding in going from $\mathrm{Cr}$ to $\mathrm{E} 106$.

\section{Acknowledgments}

This work was supported by the Gesellschaft für Schwerionenforschung (GSI), Darmstadt. The authors acknowledge many useful discussions with experimentalists working in this area. They especially appreciate cooperation with E. Johnson and A. Rosen.

\section{References}

1 B. Fricke and J.T. Waber, Actinides Rev, 1 (1971) 433.

2 B. Fricke, Struct. Bond., 21 (1975) 89.

3 J.-P. Desclaux and B. Fricke, J. Phys., 41 (1980) 943.

4 V.A. Glebov, L. Kasztura, V.S. Nefedov and B.L. Zhuikov, Radiochim. Acta, 46 (1989) 117.

5 E. Johnson, B. Fricke, O.L. Keller, Jr., C.W. Nestor, Jr., and T.C. Tucker, J. Chem. Phys., 93 (1990) 8041.

6 H.W. Gäggeler, D.T. Jost, J. Kovacs, U.W. Scherer, A. Weber, D. Vermeulen, J.V. Kratz, M.K. Gober, H.P. Zimmermann, M. Schädel, W. Brüchle, I. Zvara, A. Türler, K.E. Gregorich, R.A. Henderson, K.R. Czerwinski, B. Kadkhodayan, D.M. Lee, M. Nurmia and D.C. Hoffman, Radiochim. Acta, 57 (1992) 93.

7 J.V. Kratz, H.P. Zimmermann, U.W. Scherer, M. Schädel, W. Brüchle, K.E. Gregorich, C.M. Gannett, H.L. Hall, R.A. Henderson, D.M. Lee, J.D. Leyba, M.J. Nurmia, D.C. Hoffman, H. Gäggeler, D. Jost, U. Baltensperger, Ya Nai-Qi, A. Türler and Ch. Lienert, Radiochim. Acta, 48 (1989) 121.

8 B. Fricke and E. Johnson, Radiochim. Acta, in press.

9 V. Pershina, B. Fricke, G.V. Ionova and E. Johnson, J. Phys. Chem., in press.

10 E. Johnson, personal communication, 1993.

11 J.P. Desclaux, At. Data Nucl. Data Tables, 12 (1973) 311.

12 V. Pershina and B. Fricke, J. Chem. Phys., 99 (1993) 9720.

13 C.E. Moore, Ionization Potentials and Ionization Limits Derived from the Analyses of Optical Spectra, NSRDS-NBS 34, 1970, (SD Catalog No. C 13.48:34, National Standards Reference Data Series, National Bureau of Standards, Washington, DC).

14 R.D. Shannon, Acta Crystallogr., A 32 (1976) 751.

15 V. Pershina, W.-D. Sepp, B. Fricke and A. Rosen, J. Chem. Phys., 96 (1992) 8367.

16 V. Pershina, W.-D. Sepp, B. Fricke, D. Kolb, M. Schädel and G.V. Ionova, J. Chem. Phys., 97 (1992) 1116.

17 V. Pershina, W.-D. Sepp, T. Bastug, B. Fricke and G.V. Ionova, J. Chem. Phys., 97 (1992) 1123.

18 V. Pershina and B. Fricke, J. Phys. Chem., in press.

19 A. Rosen and D.E. Ellis, J. Chem. Phys., 62 (1975) 3039.

20 G.V. Ionova, V. Pershina, E. Johnson, B. Fricke and M. Schädel, J. Phys. Chem., 96 (1992) 11096.

21 S.G. Bratsch and J.J. Lagowski, J. Phys. Chem., 90 (1986) 307.

22 V. Pershina and B. Fricke, Radiochim. Acta, in press.

23 V. Pershina, B. Fricke, J.V. Kratz and G.V. Ionova, Radiochim. Acta, 64 (1994) 37. 